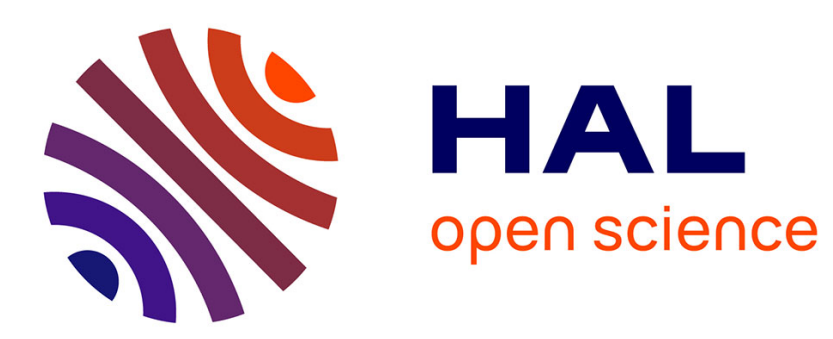

\title{
Internet Platform for City Dwellers Based on Open Source System \\ Łukasz Przysucha
}

\section{To cite this version:}

Łukasz Przysucha. Internet Platform for City Dwellers Based on Open Source System. 4th IFIP International Workshop on Artificial Intelligence for Knowledge Management (AI4KM), Jul 2016, New York, NY, United States. pp.106-118, 10.1007/978-3-319-92928-6_7 . hal-01950011

\section{HAL Id: hal-01950011 \\ https://hal.inria.fr/hal-01950011}

Submitted on 10 Dec 2018

HAL is a multi-disciplinary open access archive for the deposit and dissemination of scientific research documents, whether they are published or not. The documents may come from teaching and research institutions in France or abroad, or from public or private research centers.
L'archive ouverte pluridisciplinaire HAL, est destinée au dépôt et à la diffusion de documents scientifiques de niveau recherche, publiés ou non, émanant des établissements d'enseignement et de recherche français ou étrangers, des laboratoires publics ou privés. 


\title{
Internet platform for city dwellers based on open source system
}

\author{
Łukasz Przysucha \\ Wroclaw University of Economics, Komandorska 118/120 53-345 Wroclaw \\ lukasz.przysucha@ue.wroc.pl
}

\begin{abstract}
Smart City is a relatively new idea developed by many business entities, organizations and residents. The world's population migrates to cities. Experts estimate that more than $65 \%$ of the global GDP will be produced by the 600 largest cities in the world in 2025. It definitely motivates to increase the intensification of activities aimed at development of urban systems which improve the efficiency of the residents and entrepreneurs working there. The author focused on a characterization and theoretical creation of the Internet Platform which will synchronize all the processes occurring in the smart city and support the development of a new ideas related with improving life in the city. The main goal of this article is to find a common ground between smart city and CMSes based on GNU GPL license which through the properties are open to development by thousands of users, fully flexible and customized for any urban area. The author suggested 10 areas of smart city which may be reflected in the portal. Usage and integration all of them may revolutionize the look on development of cities in the world.
\end{abstract}

Keywords: Smart City, platform, city dwellers, Content Management System, Open Source, GNU GPL

\section{Introduction}

The number of operations performed on the Internet continues to increase year-onyear. The network has a huge functionality and impact on society. Considering the application in the metropolitan area Internet can be a tool for a broad social communication, source of information similar to radio, newspapers, alarm for citizens in crisis situations and many more influencing lives easier. Recently there is much discussion about smart solutions in terms of the city but solutions in practice look pale. Often this is due to high costs of implementation of systems, lack of comprehensive tools and ignorance managing the city. The following article aims to propose examples of innovative solutions for cities that will be in the platform for city dwellers based on one of the free content management systems using the GNU GPL. The au- 
thor believes that the use of solutions that are currently being standardized globally, developed by millions of users and free should be implemented to create the concept of smart.

\section{Smart society}

The concept of smart city, depending on the various definitions and scopes can include many aspects of life. According to this basic smart city can be called the area (city, region, agglomeration), which consists of four elements [1]. The first of these are creative residents who are "enlightened" their activities and use their knowledge as well as develop it. Another pillar is effectively working organizations and institutions processing existing knowledge [2]. On the technical side must be ensured adequate technological infrastructure - broadband cable services in the network, digital space for data and remote tools for knowledge management. The final element is the ability to innovation. Komninos N. explains this as part of management and the ability to solve problems that appear for the first time since the innovation and management under uncertainty are key to assessing intelligence. Smart society may be divided into more detailed groups according to aspects of:

1) Smart business and economy - innovative environment for entrepreneurs. It must be flexible and easy in the law. Creative start-ups, new ideas and refreshed businesses are classified for a special care. There is a high level of productivity. Relationship of the economy are both against the local as well as global. There is also a high degree of flexibility in the labor market.

2) Human capital [3] - educated people who are not afraid to implement new ideas. A wide variety of force. The universities educate specialists in their fields. In addition to running his own family and work, people have time for social activities and are open to others. They participate actively in community life.

3) Management - the power is handed over to the residents. Urban sector is divided between education, work and residents. Residents have easy ability to communicate.

4) Mobility - clean and efficient transport system, an integrated system for traffic control.

5) Environment - development planning, smart resource management, investments in renewable energy sources, clean the foreground.

6) Quality of life - safe neighborhood, a high level of health care, easier access to public services, tourist attractions, good housing conditions and constantly revised level of prosperity. 


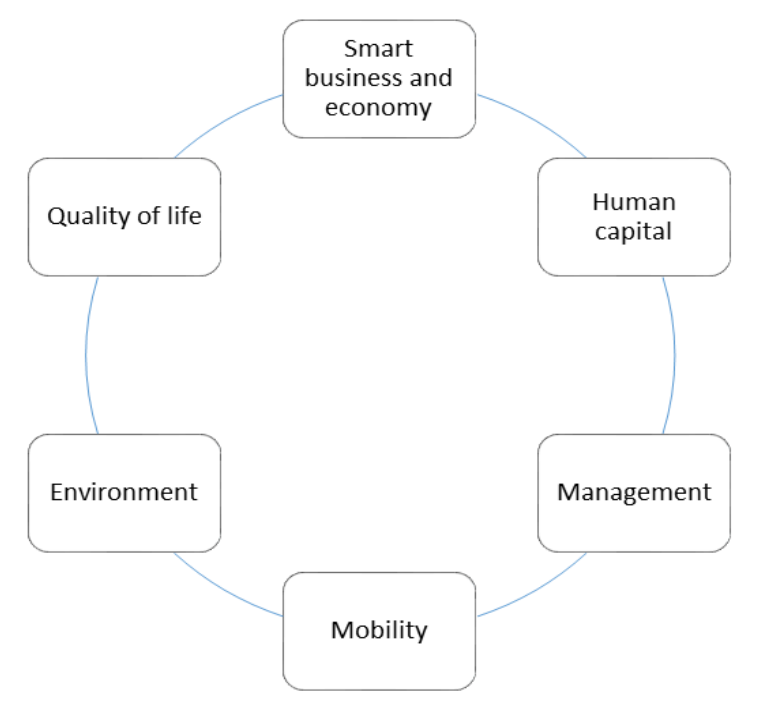

Fig 1. One of the proposed schemes of smart city.

The author of this work is that the main consolidator of the above factors can be innovative platform for city dwellers. It could integrate all the parts together and facilitate the development of each individual. It is true that there are many websites dedicated for metropolitan areas but they have the assumption transmit only messages from the press and public offices. They do not allow interaction between residents. Considering the wider national IT clusters providing facilities information they have similar assumptions - to integrate the participants, strengthen innovation and technology, and to build a strong position compared to other countries. Their main objectives are the integration of the national information technology, promotion of sustainable urban development, promotion and implementation of the concept of smart grid, creating an area of cooperation between IT companies, universities, and government support for innovation in the economy, the acquisition of human capital and knowledge, and many others. With the full cooperation between research centers, managers of cities and private companies it is possible to fully implement the concept of intelligent city. It is important that the idea of smart city was developed around the world, and that the resources allocated to it is still growing, because, according to forecasts [4] from 2010 until 2025 . $65 \%$ of the global GDP will be produced by the 600 largest cities in the world. Therefore, implementation of the idea of smart city can have a direct impact on increasing the efficiency of our civilization.

In recent years many start cities refer to ecology [5]. Clean water, air and soil related issues are discussed at numerous international conferences and reports. Please note that in order to implement ecological aspects, rules and standards, cities must keep the rules and standards and implement appropriate technologies. 


\section{The concept of Internet Platform based on Smart City}

As already noted, Smart City is largely composed of several components [6]. The people of the Smart community are not the only ones, but they are also supporting their technology and institutions. Strategic directions in key dimensions are also important. There are strategic principles that, once fulfilled, can change the shape of the Smart Society to a much more advanced.

The first one is the integration of technological factors. This methodology includes not only the focus on the technical aspects that hook up the infrastructure, machinery and equipment. It is well known that hardware issues are essential to the functioning of many entities and projects, but considerable attention should be paid to the assumptions and functioning of systems. The concept of urban portal discussed in the article carries many risks. It is first dealing with the complexity of many elements. For example, downloaded data from devices that use city navigation will be in real-time mode for an interactive map that will define traffic in the streets. This is a huge complexity of the information being sent. In the case of several million cities, even if some of the inhabitants will be using the application at that time, a large amount of data will be generated and processed. Based on these reports, further traffic reports may be generated in the city and proposed further solutions to eliminate congestion and traffic jams in the streets. Another example may be a map of the actual temperature that will be transmitted immediately using a drones network that makes meteorological images. In many cases the cities are large, vary in height, and can be met with completely different measurements in one district and another across the city. Thanks to such images and accurate real temperatures, residents would be sure that the temperature and atmospheric conditions of a given location are accurate to the street. Examples may be more, but it is worth noting the data obtained from this type of project. It should be standardized in one format so that it can be aggregated and used for further work. Technology in Smart City is not only the ability to improve the standard of living of the people, but also the ability to estimate activities and create solutions for the future.

There are many solutions such Internet Platforms dedicated for urban areas. They have the usual basic features such as the provision of information from the council and news about events happening at the moment. The author considers it necessary to increase the range of functionality and make a real connection to streamline all the paths of smart city that the portal could be a tool and an integral root of the functioning of the entire smart city. It is also important that the portal could be based on an open source license. This option lets locals to develop the website the tools used in the building can be created by thousands of users and provide maximum safety.

It is worth noting that the core of the system may be available for every city the same, while extensions and functionality will be completely different. Such implementation will be very specific in comparison with other web projects. It should be noted that a large number of factors and dynamic variables are included in the platform. In this case, infrastructure and data flow will play a very important role. 
In the case of use of solutions of a private company the city is dependent on a group of several people who support the project without the involvement of people from outside. More about the use of the GNU GPL and application it during the implementation in the next section.

The issue of implementing solutions is also whether the implementation process of the solution will be coordinated, and if so to what extent by the city authorities. Work planning and concept modification can be outsourced to outsourcing companies, but it will generate additional costs and city managers may lose control of the implementation process at some point. Below is the process of designing Smart solutions for the city.

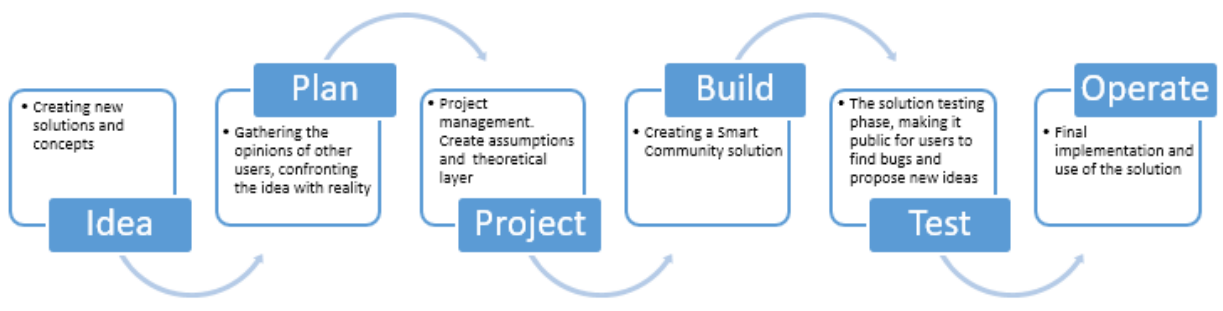

Fig 2. Process of designing Smart solution.

Another concept is to create a regional platform for city dwellers for example dedicated for one country. The server room and technical support team would be in one location. The "cloud" solution can have both advantages and disadvantages. Most cloud computing benefits are in terms of IT cost savings. In general the lack of on-premises infrastructure removes associated operational costs in the form of power, air conditioning and administration costs. One place in a given area will certainly minimize costs, however, the security issue will be discussed in this aspect. Although cloud service providers implement the best security standards and industry certifications, storing data and important files on external service providers always opens up the risks. If services are provided by an external company under the rules of outsourcing, principals should pay close attention to the security of the whole system, as the data on the links will sometimes contain confidential information. Cloud computing provides enhanced and simplified IT management and maintenance capabilities through central administration of resources, vendor managed infrastructure and SLA backed agreements. All updates in the IT infrastructure and maintenance area are eliminated, as all resources are maintained by the service provider.

The following diagram shows the cycle of information flow from the place of obtaining data to the server room. 


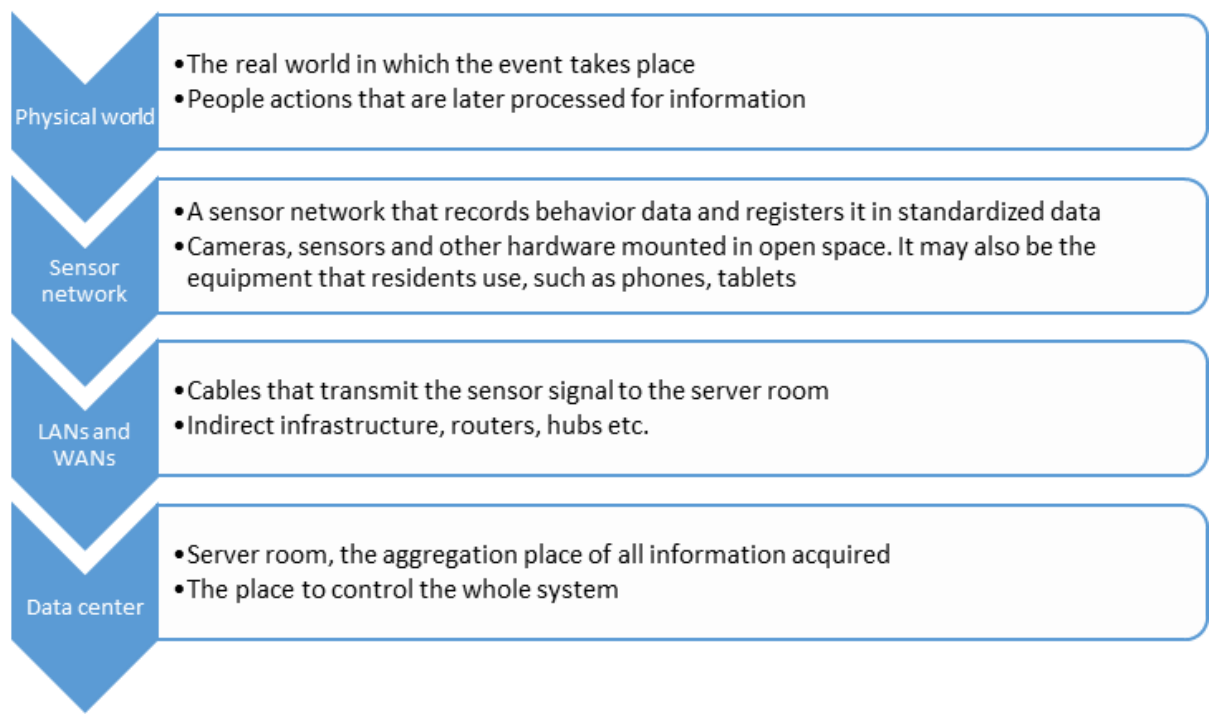

Fig 3. Elements required to Smart City Platform.

\section{Content Management Systems}

Content management systems are dynamic pages. At the beginning it is worth to define the concept of static and dynamic pages, and determine the differences between them. Classic pages had a heyday in the 90 s of the last century. Currently abandoned standardization of static pages and dynamic websites became more popular. Static pages are those portals [7], which do not change their content when calling in your browser. In order to introduce any changes on the page, the administrator is forced to overwrite the files manually. Simple part, based on HTML have both advantages and disadvantages. They are quite simple to prepare, and the whole process of creation of the site is fast. On the market there are free programs-wizards that allow you to modify portal without knowing the language. Preparation static page does not require much effort; thus it is quite cheap. The biggest use of such sites are simple business websites. They do not require a server with PHP and MySQL databases. Hosting can also be free. Unfortunately, in the case of sending the page to the server and placing on the modification, it is necessary to have a basic knowledge of creating websites. An important drawback is the lack of interaction with users. These sites serve only to provide information unilaterally without any action on the line useradministrator. They are therefore usually less interesting than the dynamic and users spend less time on them. Dynamic pages are generated in real time in front of the server HTML based on data provided by the program for browsing the Internet. These sites are dependent on the actions taken by the user is currently browsing them. For example, after adding the comment on the page there is a new entry, date added and 
author. Sometimes they are also given additional user identification data such as IP, browser, which was displayed page and the version of the system. You can change the content in two ways [8] - the first method, client-side use of scripting languages such as JavaScript and ActionScript, which make direct changes to the elements (DOM. Document Object Model). The main benefits of this method are shorter response times, much less load on the server, and a better effect of the interactive application. It is not required to interact with the database, making it easier to change the code. The second method is called server-side, using programming languages such as PHP, ASP and Perl. This processing is useful for a contact database and a permanent memory. Example of the operation is to validate the user or data exchange.

A content management system is software [9] that allows you to create, manage and publish content. Early adoption of CMS contained mainly on the management of documents and files, usually in the internal forum, now is the management of content in the network at the level of the public. The purpose of such systems is to provide an intuitive interface for viewing content users, as well as the interface for the administrator of the site, usually with the position of the panel administrator. CMSes are great help in the way of work with the system [10]:

1) Dynamic content.

2) Easy to make changes.

3) Tab for content management.

4) Addition of interactive content.

5) Integration with the media.

6) Full control over the entire site.

7) Allowing multiple people management side.

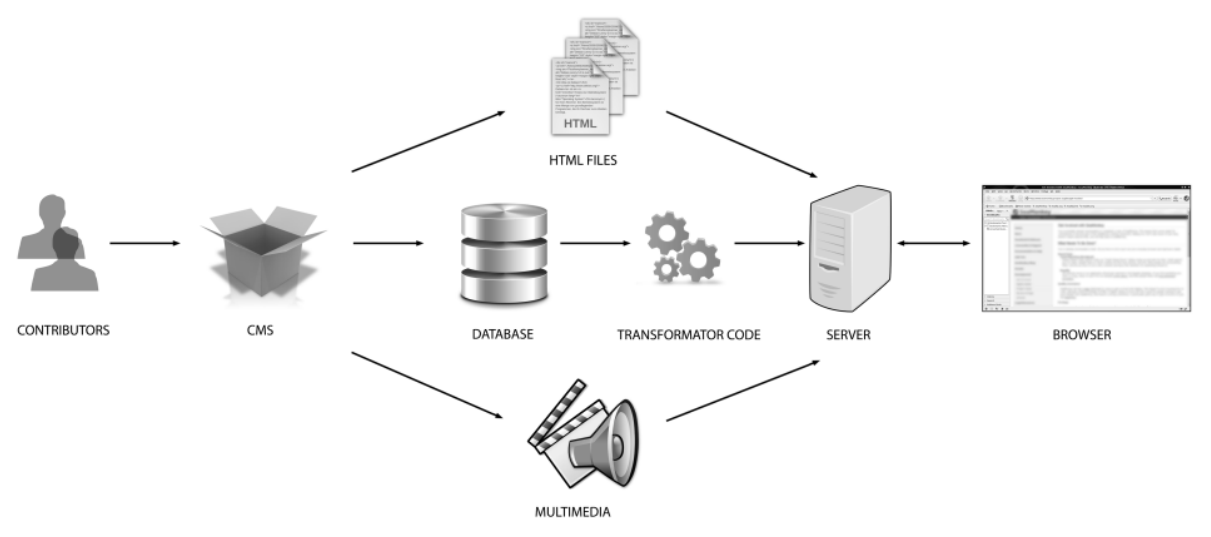

Fig. 3 Place of CMS during the page request 
Content management systems offer dynamic content operations. With WYSIWYG editors such as the administrator does not need to have knowledge of HTM and other conditions necessary to deposit the content on the page. All interference in the content is done through a web browser. Readers are kept informed about the authors, dates of creation and modification of articles.

Add, update, delete, copy selected parts are extremely quick and easy. The administrator can divide the roles of action moderators and editors according to the due rights. Thanks to attributes, the person who is the editor will get the opportunity to log on only to the content of the selected departments. It has the possibility of penetration of the system functions available to administrators the entire site. In this case, the tab content management is the administration panel. The most CMS has a fairly clean interface, intuitive user interface buttons and functions, as well as the standard visual system. Systems support an interactive content such as discussions, class schedules for students, staff cards or surveys. This is thanks to support for multiple languages. For example, the CMS can be written in PHP, but the content on the site are added in HTML or script administrator deposited in JavaScript. This openness gives also a large integration with the media. On the one side can be placed graphics, video, advertising in Flash technology and many others. A super administrator with all privileges can control the entire site and all users. In addition to the admin panel is a panel important place on the server and access to ftp. New updates and documents can be sent directly from the system, but it is recommended to also have access to the files in the directories on the server. An important place in addition to the admin panel is a panel on the server and access to ftp. New updates and documents can be sent directly from the system, but it is recommended to also have access to the files in the directories on the server.

The most popular CMSes like WordPress, Joomla or Drupal are based on GNU GPL license. It means [11]:

1. The freedom to run any program under this license, regardless of the purpose.

2. Freedom to analyze and modify the program for improvement.

3. Freedom to provide a program to help other users.

4. The freedom to improve the program and distribute their own modifications. It refers to the entire community.

In most cases, open source CMS means better quality [12]. The code is created by thousands of people [13]. 
The advantages of open source code pages:

1. Users do not pay for the system and add-ons available on the Internet. There is a large number of public and free graphic templates.

2. The code is updated regularly for the most popular systems like WordPress or Joomla. Thanks to the huge community of protection against attacks are high.

3. Easy migration between servers. The current standards of free CMSs allow simple data export and import if user move the site to another server on the network. It is just necessary to install the plugin and copy the generated files.

4. Intuitive interface developed over several years with thousands of users. Both administrative panels like front-end sites have a simple scheme that fits the standard user. Thanks to the appropriate layout, using the site does not require advanced programming knowledge.

The disadvantages of open source code pages:

1. Increased amount of spam, such as updates, occasional ads, system notifications from creators.

2. No custom applications. For individual processes and mechanisms, opensource systems may not include such functionality.

3. Not all platforms are up-to-date and supported by developers and communities. Only the most popular types of WordPress, Joomla, Drupal have full support and 24/7 support for users and administrators.

4. Users do not have manufacturer's warranty in case of hacking, other undesirable actions. In this case, administrator risks installing on his own responsibility and in the event of problems he need to contact the private companies supporting the systems or trust the community of the system.

The advantages of own content management platform:

1. Paid CMSs are more applicable to niche projects where standard solutions are not enough. For a reasonable fee, user will receive every product he desire.

2. High consistency of all modules. If the system is created by one programmer or one team, all elements are more consistent and fit together.

3. The creators of commercial solutions have an individual approach to the client. For larger companies, users get a product warranty and, in case of failure, immediate technical support and possible compensation. Users are confident that the developer will check the problem and help.

4. When buying an individual solution, users can ensure their uniqueness. By paying for an exclusive license, they are assured that the graphical interface or mechanism of action will not be used on any other website on the Internet. 
The disadvantages of own content management platform:

1. The system user must pay for his purchase, often also for technical support and operation. Manufacturers also demand fees for additional extensions and plugins, as well as new graphical interfaces.

2. Managing such a system is often more difficult than free solutions, because it is based on copyrighted ideas and assumptions, is not up to standards.

3. Authorized systems are heavy in personalization. For CMS with open code, user can view available extensions and build a site by adding existing modules. In case of commercial applications, usually tools are written from scratch and the final effect can only be seen after the order has been fulfilled.

4. For small businesses, systems may not be fully secure, because of the many attack possibilities and a small number of IT supporters. It is necessary to make frequent copies and in the event of an attack, to secure the holes (learning errors more, compared to open source and thousands of programmers supporting the project).

\section{The usage of CMS as a platform for city dwellers}

Content management systems such as WordPress, Joomla or Drupal, based on the GNU GPL are the ideal solutions for implementation of platform for city dwellers. Their flexibility and great functionality may be the root for the further development of the website, which will not necessarily cost a fortune in setting up and subsequent maintenance. Thousands of users around the world verify the safety and mistakes every time.

The author decided to divide the functionality of the portal on 10 spheres, which are integral with each other, but are responsible for other areas of everyday citizen. They are: smart business, smart human capital, smart management, smart environment, smart transportation, smart IT, smart everyday life \& communication, smart care and smart future.

Each of them can be implemented in the portal so that the resident had a real impact on the operation of the city. The following is a discussion of each of them and the general scheme of the site. Every professional website must have the appropriate interface to their functionality and target the visitor. Most portals for content management like WordPress, Joomla or Drupal have a large possibility to modify the creation and appearance, and their functionality is virtually unlimited. It's important to customize every website for all users and target. The site should also be adapted for blind people and deaf. The appearance must be clear and simple, but at the same time modern. Important information concerning the accident or alert on important matters should be available in a place that is qualified to "method of 5 seconds" [14]. The following sections should be submitted to the above sections in the field of smart city, each in a different color. 


\begin{tabular}{|c|c|}
\hline Smart Business & $\begin{array}{l}\text { - Support for investors } \\
\text { - Business events in the city }\end{array}$ \\
\hline Smart human capital & $\begin{array}{l}\text { - Knowledge groups } \\
\text { - Bank of competense }\end{array}$ \\
\hline Smart Management & $\begin{array}{l}\text { - Communication between } 4 \text { gropus of community } \\
\text { - Referendums and votings }\end{array}$ \\
\hline Smart Environment & $\begin{array}{l}\text { - Smart Trash with a geolocation } \\
\text { - Sensors system }\end{array}$ \\
\hline Smart Transportation & $\begin{array}{l}\text { - Position of the vehicles } \\
\text { - City parking system }\end{array}$ \\
\hline Smart IT & $\begin{array}{l}\text { - IT services and maps } \\
\text { - Comprehensive package in the cloud for residents }\end{array}$ \\
\hline $\begin{array}{l}\text { Smart Everyday Life } \\
\& \text { Communication }\end{array}$ & $\begin{array}{l}\text { - Social media for residents } \\
\text {-Search people by personality } \\
\text { - Smart shopping with RFID technology } \\
\text { - Supporting in daily activities }\end{array}$ \\
\hline Smart Care & $\begin{array}{l}\text { - Consultations with doctors } \\
\text { - On-line prescriptions }\end{array}$ \\
\hline Smart Future & $\begin{array}{l}\text { - Planning for the further development of ideas } \\
\text { - Control of the other modules }\end{array}$ \\
\hline
\end{tabular}

Fig 4 Internet Platform for city dwellers. Suggested modules.

Smart business - this is an area for residents engaged in business in the city, those who would like to review the offer opportunities to invest in the city, made cooperation with other cities and stakeholders. The interactive map should easily show locations of businesses to buy and invest. In addition to issues relating directly to the agglomeration should appear more universal elements for investors and residents themselves, such as trading companies and municipal rates. Users should be able to comment information from the business world. Another map should contain full information about the business events areas of the city. They can be added by the users and moderated by the staff offices. An important element that should be in the fold for entrepreneurs is counter debts. It is not designed for the same business, but also for the citizens. On the one hand, each user can monitor municipal finances, but on the other hand entities that want to invest can confirm the stability of the monetary au- 
thorities of management of agglomeration. There should be a special area for start-ups operating in the city.

Smart human capital has the task of improving the skills of citizens in all aspects of life and their proper allocation between the residents, universities and businesses. In this section, we should clearly present the full offer of universities and as well as create a "bank of competence", where users can exchange knowledge, information, aggregate inhabitants in the group of data fields in easy way. It is also valuable information for companies creating jobs in the city. Keep in mind that human capital is infinite added value for the city and the budget for development and increase should be large. Panel management should facilitate communication between citizens, civil servants, businesses and universities. Every citizen should have a direct influence on the decisions of city council through referendums and citizens' budgets. This can be easily solved thanks to the accounts of residents in the voting module integrated with the entire portal. In order to fully authenticate the identity of the residents, they can confirm their choices and voting by introducing a code received in the text message.

Smart Management is a part of the whole scheme that is responsible for the fully cooperation between city council with president of a city, universities, business entities and the social side. The tab should liquefy communication between these groups.

Smart Environment is a module that easily should provide information about the city. The author proposes here several innovative solutions that significantly simplify the management of the environment in the city. The tab will be considering smart trash system, which easily will inform about the pollution in the street. Thanks to geolocation, resident walking down the street can push the button on his mobile device, which tells the city council about considerable pollution. There is also taken a picture during sending the information. Officials using of these data estimate the amount of priority and generate a new request to the municipal services with a call to intervene. With time due to changes in the law may be chosen a company, which is responsible for the full process, from infrastructure through the information center at the city office, ending on managing the machines and employees of cleaning companies. A slightly different offer, but in a similar range can be offered to residents of single-family property, and government housing. By installing special sensors in the storage areas of waste can easily inform residents about the approaching overflow buckets and automatic call maintenance services. Residents with applications of Business Intelligence will be able to verify reports of fees and the number of call services.

Smart Transport is both public transport and private cars. Municipal vehicles should be promoted, because by reducing the amount of private cars decrease traffic jams and exhaust fumes. Solutions that can be delivered in the city dwellers platform in the most will be available in the mobile version - primarily geolocation module buses and trams. When you turn connection to the satellites you will be able to determine its current position and find the vehicles in real time on the selected filters which tram is the nearest looking at the current traffic, or whether it will be possible to change between the delayed bus and tram arriving as planned. Virtualization is very popular nowadays and can promote the popularization of urban transport. What more private drivers could use the portal page by synchronizing with sensors placed at 
parking in the whole city. Proper algorithm could determine the free parking spaces with an indication of the closest located from your current location.

The IT area allows residents access to the latest technologies. The portal could have a map of access points to the network, a list of the buses where travelers have possibilities to charge their electronics devices on the board, infographics that define the speed of the Internet in different areas in the city, elements informing about the technology provided by mobile networks and digital signal. As part of the account, each user could ultimately receive an e-mail account from the domain of the city, cloud storage for files and ftp account with databases to create a business card in the Internet. Smart IT should support both ordinary citizens in their daily duties and activities as well as entrepreneurs focus their network and promote outside the agglomeration.

Smart everyday life \& communication is combined into one tab because interpersonal communication is an integral part of everyday life and it is essential that all these processes were performed. The website would also comply with a social function, so people in the area could get to know each other, organize joint events, assist in discussion groups and forums and develop a community network, which will be the nucleus of the real society. Portal could segregate people by profession, age, common interests. It will be support to finding the staff to companies, friends to the cinema or to organize a thematic meeting. Smart shopping module could help shopping in the store. In principle, residents would get a magnetic card, which can be an integrated part of their wallet. All the goods in the store would be equipped with a RFID card, which after crossing the gate at the exit of the store to read and lent to an electronic card, which is directly linked to a bank account. Notification of mobile application will be sending a request whether the resident made shopping for that amount and will be required to identify him via a password. In the case of successful verification and collection of money from the account. Next, the exit door is automatically open and the resident may leave the store. The aim of these measures is to reduce the number of "smart" solutions in the one place and create an universal interface to perform many tasks.

Smart care is a module responsible for the health of residents. Each patient through the portal will be able to book a visit with a doctor to verify results of test, check the status of prescription and order pharmaceuticals online. By installing special medical equipment portal will be able to send reports on the state of health of the doctors.

Smart Future is the last area responsible for the development of the city and the idea of a smart city. It will monitor the remaining 9 modules and show the further development directions. Residents will be able to conduct their own studies and projects within the smart city, and the tab will promote and popularize the most interesting ones. 


\section{Conclusion}

The creation of the Internet Platform for city dwellers, which includes 10 of mentioned above areas based on content management systems under the GNU GPL open a new path in the development of smart city. The combination of all these aspects in one place will increase the efficiency of internal processes and improve the exchange of information. It is also important to standardize all schemes, systems and applications, which work in the field of the platform. Each city is guided by a different specificity and has other conditions, however part of the functionality is shared by all. It is worth considering creating one central core of the system for several cities in a nearby location and designing dedicated solutions for each locality. Content management systems based on open source have the ability to maintain the platform for dwellers. Unfortunately, currently, despite the many thousands of add-ons and extensions there is no clearly defined path of development systems in terms of smart city. This also applies to the business path that can take place when developing urban solutions using open source as well as scientific. There is no literature in the area that specifies the development of content management systems in relation to smart city.

The article was intended to familiarize the issues related to the use of systems with virtualization implementations of the city, as well as suggest the examples of innovative solutions which will enhance the safety and quality of life of every citizen. The author believes that the popularization of content management systems based on open source code in relation to smart city issues may in the future create solutions to help human development. Year after year, we are witnessing a growing computerization of society and the problem of humanity moving from rural to urban areas. In many cases, it may be the implementation of information systems that will monitor many factors in the city, reduce traffic jams, facilitate access to medical care for residents, and help report incidents. 


\section{References}

1. Komninos N., Intelligent Cities and Globalization of Innovation Networks (2008), p. 17

2. Understanding Smart Cities: An Integrative Framework (2012)

3. Smart Cities: Big Data, Civic Hackers, and the Quest for a New Utopia (2013), p. 93

4. Urban World: Cities and the Rise of the Consuming Class, McKinsey Global Institute

5. Mercier-Laurent E., What technology for efficient support of sustainable development. (2015)

6. Conceptualizing Smart City with Dimensions of Technology, People, and Institutions (2011)

7. http://www.edinteractive.co.uk/article/?id=4

8. http://www.seguetech.com/blog/2013/05/01/client-side-serverside-code-difference

9. http://www.techterms.com/definition/cms

10. Mehta N., Choosing an Open Source CMS. Beginner's Guide, Packt Publishing (2009), p. 19

11. Lindberg V., Intellectual Property and Open Source (2008), p. 341-354

12. Weber S.: The Success of Open Source (2004), p. 54

13. Connor C., How To Create A Website For Business Or Personal Use (2013), p. 17

14. Johnsen M. Multilingual Digital Marketing: Become The Market Leader (2016), p. 26 